\title{
ANALISIS KESEJAHTERAAN MIGRAN DI INDONESIA
}

\begin{tabular}{|c|}
\hline Nufi Alabshar ${ }^{\mathbf{1}}$, Sri Rum Giyarsih \\
${ }^{2}$, Agus Joko Pitoyo \\
${ }^{1}$ Badan Pusat Statistik Provinsi Kalimantan Barat \\
${ }^{2,3}$ Fakultas Geografi, Universitas Gadjah Mada, Yogyakarta \\
${ }^{1}$ aalbps@ @ps.go.id, ${ }^{2}$ srirum@ugm.ac.id, ${ }^{3}$ aguspit@ ugm.ac.id \\
\hline
\end{tabular}

Diterima: Maret 2020; Disetujui: September 2020

\begin{abstract}
Migration is one of the solutions for survival. Furthermore, migration also provides an opportunity to improve the economy and family welfare. In addition to positive impacts, migration also has negative impacts. These positive and negative impacts make migrant welfare as a result of migration is interesting to study. This study aims to analyze how is the welfare of migrants when viewed through the variable of housing and asset ownership. This study uses secondary data sourced from 2015 Inter-Census Population Survey data (SUPAS 2015). The description of migrant welfare is seen through the housing quality and asset ownership. The results showed that through housing and asset ownership variables, migrants tend to have a good welfare even if compared to non-migrants. This shows the important role of the government in accommodating both the distribution of migration flows and the equitable distribution of resources in Indonesia.
\end{abstract}

Keyword: housing quality, migration, migrant welfare.

Abstraksi. Migrasi merupakan salah satu solusi dalam bertahan hidup. Lebih jauh lagi, migrasi juga memberi kesempatan untuk meningkatkan ekonomi dan kesejahteraan keluarga. Selain dampak positif, migrasi juga mempunyai dampak negatif. Dampak positif dan negatif ini membuat kesejahteraan migran sebagai akibat dari migrasi menjadi menarik untuk diteliti. Penelitian ini bertujuan untuk menganalisis bagaimana kesejahteraan migran jika dilihat melalui variabel perumahan dan kepemilikan aset. Penelitian ini menggunakan data sekunder yang bersumber dari data Survei Antar Sensus Tahun 2015 (SUPAS 2015). Analisis yang digunakan merupakan analisis deskriptif dan uji hubungan. Gambaran kesejahteraan migran dilihat melalui kualitas rumah tempat tinggal dan kepemilikan aset. Hasil penelitian menunjukkan bahwa melalui variabel perumahan dan kepemilikan aset, migran cenderung untuk memiliki kesejahteraan yang baik bahkan jika dibandingkan dengan non migran sekalipun.

Kata kunci: kualitas perumahan, migrasi, kesejahteraan migran.

\section{PENDAHULUAN}

Salah satu permasalahan dalam kependudukan yang terjadi di Indonesia adalah terjadinya ketimpangan dalam pembangunan, ketimpangan ini mengakibatkan terjadinya perbedaan pembangunan dan tingkat ekonomi antar daerah. Pertumbuhan ekonomi tanpa diikuti oleh pemerataan ekonomi akan memperlebar jurang pemisah antara satu kelompok masyarakat dan kelompok lainnya (Rubiarko \& Sakti, 2013). Salah satu solusi dalam mengatasi ketimpangan kesejahteraan tersebut adalah migrasi. Berdasarkan data Badan Pusat Statistik (BPS), lebih dari separuh penduduk Indonesia atau sebesar 57 persen dari jumlah penduduk, tinggal di Pulau Jawa yang hanya memiliki luas sebesar 7 persen dari total luas daratan Indonesia (BPS, 2016), data tersebut menunjukkan 
bagaimana ketimpangan distribusi penduduk yang ada di Indonesia.

Migrasi memiliki peranan penting dalam demografi dan dinamika penduduk. Pola pergerakan migrasi di Indonesia semakin berkembang. Pulau Jawa masih menjadi pulau favorit sebagai tujuan migrasi, namun, migrasi dari Pulau Jawa ke pulau lainnya juga sudah mulai bertambah dari waktu ke waktu (Nugroho \& Pitoyo, 2017). Perubahan dan dinamika migrasi yang cepat membuat permasalahan migrasi semakin kompleks. Volume migrasi yang semakin besar juga menimbulkan kerumitan dalam masalah demografi (Tajudin, Rijanta, Yunus, \& Giyarsih, 2015).

Seperti yang disebutkan Lee (1966) dan Todaro (1969), dan sebagaimana dengan teori pendahulunya Ravenstein (1889), motif ekonomi merupakan motif yang dominan sebagai penyebab migrasi. Motif ini muncul karena didasari dengan adanya harapan untuk memperoleh pendapatan yang lebih tinggi demi peningkatan kesejahteraan dibandingkan dengan saat masih berada di daerah asal. Lebih jauh lagi, migrasi juga dijadikan sebagai cara untuk bertahan hidup serta untuk memperoleh kesejahteraan (White et al., 2014). Banyak penelitian yang menyebutkan bahwa migrasi mampu menyejahterakan migran di daerah tujuan. Irawaty \& Wahyuni (2011) dan Tajudin et al. (2015) menyebutkan migrasi dapat meningkatkan pendapatan, bahkan akhirnya mampu untuk memberikan transfer baik berupa barang maupun informasi terhadap rekanan dan keluarga di daerah asalnya.

Sebagaimana halnya dengan dampak positif migrasi, dampak negatif dari migrasi juga kerap ditemui oleh migran. Kecenderungan migran untuk bermigrasi ke daerah tertentu dapat menyebabkan terjadinya over population di daerah tersebut. Over population penduduk berdampak buruk pada ketenagakerjaan di daerah tujuan, yaitu terjadinya peningkatan pengangguran. Hal ini terjadi karena ketidakseimbangan antara permintaan dan penawaran tenaga kerja. Daerah tujuan tidak bisa menampung seluruh pendatang yang mencari pekerjaan. Akibatnya, justru meningkatkan timbulnya kemiskinan (Amalia, 2012; Mahsunah, 2013). Lebih lanjut lagi, para pencari kerja yang tidak mampu bersaing di sektor formal, merambah ke sektor informal sebagai cara untuk tetap bertahan hidup. Akibatnya, sektor informal menjadi "Plan B" bagi mereka yang tidak mampu bersaing dalam sektor formal di daerah tujuan (Elgin \& Oyvat, 2013).

Dampak negatif tersebut menjadi tanda bahwa masih ada migran yang tidak mampu memperoleh kesejahteraan walau telah melakukan migrasi sekalipun. Hal tersebut membuat tujuan utama dari migrasi tidak tercapai. Paradoks ini membuat kesejahteraan migran yang merupakan tujuan dari proses migrasi semakin menarik untuk diteliti.

Terkait hal yang telah disampaikan, dapat diketahui bahwa migrasi merupakan sarana pemerintah untuk melakukan pemerataan distribusi penduduk Indonesia. Bagi individu, migrasi merupakan salah satu strategi untuk bertahan hidup dan keluar dari garis kemiskinan. Lebih jauh lagi, migrasi merupakan jalan dalam meningkatkan kesejahteraan ekonomi baik bagi individu maupun rumah tangga. Banyak penelitian yang menyatakan bahwa migrasi adalah cara untuk meningkatkan ekonomi, namun tidak sedikit pula penelitian yang mengungkapkan dampak negatif dari migrasi. Meningkatnya skala 
mobilitas penduduk, dinamika migrasi, dampak yang diakibatkan migrasi, serta meningkatnya perhatian pemerintah mengenai migrasi, menunjukkan bahwa migrasi merupakan hal yang sangat penting untuk dikaji.

Berdasarkan paparan di atas, maka penelitian ini bertujuan utama untuk mengetahui kondisi kesejahteraan migran di Indonesia dilihat dari kualitas perumahan dan kepemilikan aset yang dimiliki. Kualitas perumahan dilihat dari jenis dan bahan baku rumah serta fasilitas yang dimiliki rumah tersebut. Sedangkan kepemilikan aset dilihat dari kepemilikan barang yang dimiliki rumah tangga migran maupun non migran.

\section{METODE PENELITIAN}

Penelitian ini menggunakan data Survei Penduduk Antar Sensus Tahun 2015 (SUPAS 2015). SUPAS 2015 merupakan salah satu survei kependudukan yang dilaksanakan di antara dua sensus. Tujuan dilaksanakannya SUPAS 2015 antara lain untuk memperkirakan jumlah, distribusi, dan komposisi penduduk, serta untuk dapat memperkirakan karakteristik kependudukan sebagai parameter demografi (BPS, 2015). Migran yang dimaksud dalam penelitian ini mencakup migran risen, migran semasa hidup, dan migran kembali. Adapun variabel-variabel yang digunakan pada penelitian ini antara lain status kepemilikan rumah, jenis lantai, luas lantai, penerangan, sumber air minum, fasilitas BAB, serta kepemilikan barang-barang tahan lama. Variabel kualitas rumah dan kepemilikan aset dijadikan indikator kesejahteraan sehingga diharapkan mampu untuk menggambarkan tingkat kesejahteraan migran.
Metode analisis yang digunakan dalam penelitian ini adalah analisis deskriptif dengan menggunakan tabel dan gambar. Analisis deskriptif digunakan agar mendapat gambaran tingkat kesejahteraan migran secara jelas. Selain itu penelitian ini juga menggunakan uji hubungan untuk menguatkan hasil temuan yang didapatkan.

\section{HASIL DAN PEMBAHASAN}

\section{Status Kepemilikan}

Gambar 1 menunjukkan sebagian besar migran tinggal di rumah milik sendiri (73,28 persen), hanya sebagian kecil saja yang masih menempati rumah kontrak atau sewa (18,17 persen) dan lainnya seperti rumah dinas dan rumah adat ( 8,55 persen).

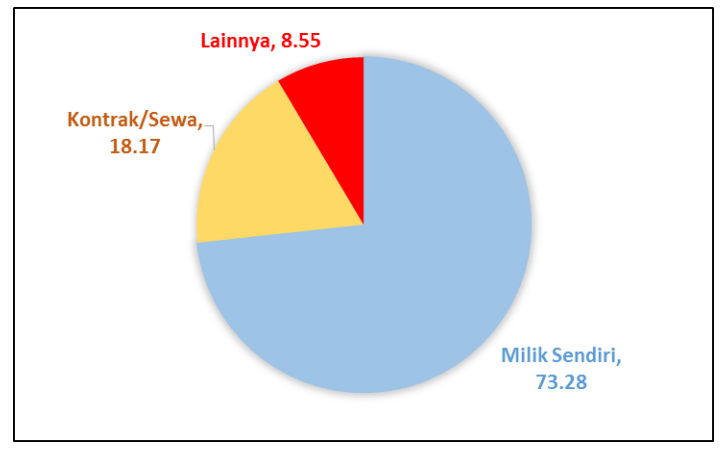

Gambar 1. Persentase Kepemilikan Rumah Migran di Indonesia, 2015

Sumber: Data Supas 2015 (diolah)

Jika status kepemilikan rumah dibagi berdasarkan klasifikasi wilayah, dapat dilihat pada tabel 1 bahwa migran yang menempati rumah kontrak hampir seluruhnya berada di wilayah perkotaan dan hanya sedikit saja yang di wilayah perdesaan. Hal ini terjadi dikarenakan tingginya harga rumah dan tanah di wilayah perkotaan sehingga sulit untuk memiliki rumah milik sendiri di perkotaan terutama bagi migran yang baru saja datang di perkotaan. 
Tabel 1.

Persentase Status Kepemilikan Rumah Migran Berdasarkan Klasifikasi Wilayah di Indonesia Tahun 2015

\begin{tabular}{lccc}
\hline \multirow{2}{*}{ Wilayah } & $\begin{array}{c}\text { Milik } \\
\text { Sendiri }\end{array}$ & $\begin{array}{c}\text { Kontrak/ } \\
\text { Sewa }\end{array}$ & Lainnya \\
\hline Perkotaan & 67,63 & 8,04 & 8,04 \\
Perdesaan & 86,26 & 9,70 & 9,70 \\
Jumlah & 73,28 & 8,55 & 8,55 \\
\hline
\end{tabular}

Sumber: Data Supas 2015 (diolah)

\section{Jenis Lantai}

Jenis lantai berhubungan secara tidak langsung terhadap kesehatan penghuninya. Hal ini dikarenakan jenis lantai mempengaruhi dalam hal kelembaban rumah (Padmonobo et al., 2012). Tabel 2 menunjukkan bahwa migran yang bertempat tinggal di Pulau Jawa, hampir

seluruhnya menggunakan lantai ubin $(84,26$ persen) dan semen (11,05 persen), sisanya hanya sebagian kecil yang menggunakan kayu atau bahan lainnya yaitu masingmasing sebesar 0,94 persen dan 3,20 persen. Hasil tersebut menunjukkan bahwa tingkat kesejahteraan migran di Pulau Jawa yang cukup tinggi, terlihat dari persentase lantai rumah yang hampir seluruhnya menggunakan keramik/ubin. Hasil tersebut sangat wajar, karena Pulau Jawa menjadi primadona sebagai tujuan migrasi di Indonesia. Hal ini sejalan dengan penelitian yang pernah dilakukan sebelumnya, di mana Pulau Jawa merupakan salah satu tempat tujuan migrasi yang begitu diminati serta memiliki migrasi neto yang positif (Nugroho \& Pitoyo, 2017; Bukit \& Pitoyo, 2018).

Tabel 2.

Persentase Jenis Lantai Rumah Migran Berdasarkan Pulau di Indonesia

Tahun 2015

\begin{tabular}{lllll}
\hline \multicolumn{1}{c}{ Pulau } & Ubin & Semen & Kayu & Lainnya \\
\hline Sumatera & 38,26 & 50,96 & 7,13 & 3,65 \\
Jawa & 84,81 & 11,05 & 0,94 & 3,20 \\
Bali-Nusa Tenggara & 57,06 & 33,72 & 2,48 & 6,74 \\
Kalimantan & 37,17 & 18,06 & 43,65 & 1,13 \\
Sulawesi & 38,77 & 38,57 & 19,49 & 3,18 \\
Papua-Maluku & 42,46 & 37,87 & 15,35 & 4,32 \\
Indonesia & $\mathbf{6 2 , 5 8}$ & $\mathbf{2 6 , 1 8}$ & $\mathbf{7 , 8 8}$ & $\mathbf{1 , 1 3}$ \\
\hline
\end{tabular}

Sumber: Data Supas 2015 (diolah)

\section{Luas Lantai}

Rumah layak huni adalah rumah yang memenuhi beberapa kriteria, salah satunya adalah kecukupan minimum luas tempat tinggal yaitu lebih dari 7,2 meter persegi per kapita, atau sekitar 29 meter persegi untuk sebuah keluarga yang terdiri dari 4 orang anggota (BPS, 2018). Semakin luas tempat tinggal migran, mengindikasikan semakin sejahtera migran tersebut karena memiliki rumah yang semakin besar. 
Tabel 3.

Persentase Jenis Lantai Rumah Migran Berdasarkan Lama Bermigrasi dan Luas Lantai di Indonesia Tahun 2015

\begin{tabular}{ccccccc}
\hline $\begin{array}{c}\text { Lama } \\
\text { Bermigrasi } \\
\text { (tahun) }\end{array}$ & $<28$ & $28-35$ & $36-48$ & $49-63$ & $64+$ & Jumlah \\
\hline 0 & 20,70 & 8,16 & 14,32 & 15,33 & 41,49 & $\mathbf{1 0 0}$ \\
$1-4$ & 18,63 & 8,76 & 15,45 & 15,73 & 41,42 & $\mathbf{1 0 0}$ \\
$5-9$ & 12,47 & 8,35 & 15,73 & 18,36 & 45,09 & $\mathbf{1 0 0}$ \\
$10-14$ & 10,25 & 8,24 & 14,52 & 19,06 & 47,93 & $\mathbf{1 0 0}$ \\
$15+$ & 7,14 & 6,57 & 13,19 & 18,58 & 54,52 & $\mathbf{1 0 0}$ \\
Total migran & 11,17 & 7,62 & 14,35 & 18,00 & 48,86 & $\mathbf{1 0 0}$ \\
\hline
\end{tabular}

Sumber: Data Supas 2015 (diolah)

Dari tabel 3 di atas dapat dilihat bahwa kelompok luas lantai yang kecil yaitu kurang dari 28 meter persegi, ditempati paling banyak oleh migran yang baru saja bermigrasi yaitu sebesar 20,70 persen. Sedangkan rumah dengan kelompok luas lantai yang paling besar, yaitu lebih dari 64 meter persegi, paling banyak ditempati oleh migran yang telah bermigrasi lebih dari 15 tahun. Dari hal tersebut dapat disimpulkan bahwa, migran yang baru saja bermigrasi akan cenderung memiliki rumah yang kecil. Hal ini karena keterbatasan yang mereka miliki di saat baru pindah atau bekerja di tempat yang baru, sehingga belum kecukupan dari segi finansial. Seiring waktu, ternyata adanya perubahan kecenderungan untuk memiliki rumah yang lebih besar dikarenakan semakin mapan dan semakin baik dari segi finansial. Hal ini sejalan dengan apa yang diungkapkan oleh Turner. Turner (1968) mengatakan bahwa Keadaan migran yang serba kekurangan di tempat baru, memaksa migran tersebut untuk tinggal seadanya, bahkan di tempat yang sempit atau tidak layak sekalipun.

Tabel 4.

Hasil Uji Cramer's V antara Lama Bermigrasi dan Luas Lantai

\begin{tabular}{llrr}
\hline & & Value & Approx. Sig. \\
\hline Nominal by Nominal & Phi & .164 & .000 \\
& Cramer's V & .082 & .000 \\
N of Valid Cases & & $5 . \mathrm{E} 7$ & \\
\hline
\end{tabular}

Sumber: Data Supas 2015 (diolah)

Jika hubungan antara lama bermigrasi dan luas lantai diuji dengan menggunakan Cramer's $V$, maka didapatkan hasil nilai Cramer's $V$ sebesar 0,082 dan tingkat signifikansi 0,000 (Tabel 4). Oleh karena $p$ - value Cramer's $V$ sebesar 0,000 $<0,05$, maka dapat ditarik kesimpulan bahwa terdapat hubungan yang signifikan antara luas lantai tempat tinggal migran dengan waktu lama migran telah bermigrasi. Hal ini 
semakin menegaskan penelitian sebelumnya, dimana semakin lama bermigrasi akan semakin sejahtera migran tersebut (Turner, 1968; Mabogunje, 1970). Hal ini telihat dari luas lantai rumah yang semakin luas, menunjukkan rumah tempat tinggal yang semakin besar yang menggambarkan semakin sejahtera migran tersebut.

\section{Penerangan}

Salah satu kriteria rumah layak huni adalah memiliki penerangan listrik (BPS, 2018). Untuk itu, listrik merupakan kebutuhan dasar dalam penerangan yang harus dimiliki oleh sebuah rumah yang layak tinggal agar dapat beraktivitas pada malam hari (Syahputra, 2017).

Tabel 5.

Persentase Jenis Penerangan Rumah Berdasarkan Status Penduduk di Indonesia Tahun 2015

\begin{tabular}{lccccc}
\hline Status & $\begin{array}{c}\text { Listrik } \\
\text { PLN }\end{array}$ & $\begin{array}{c}\text { Listrik PLN } \\
\text { Tanpa } \\
\text { Meteran }\end{array}$ & $\begin{array}{c}\text { Listrik } \\
\text { Non PLN }\end{array}$ & Lainnya & Jumlah \\
\hline Migran & 88,36 & 7,45 & 2,99 & 1.20 & 100 \\
Non Migran & 85.74 & 9,27 & 2,25 & 2,74 & 100 \\
Selisih & 2.62 & $(1,82)$ & 0,74 & $(1,54)$ & - \\
\hline
\end{tabular}

Sumber: Data Supas 2015 (diolah)

Jika dibandingkan dengan penduduk yang tidak pernah melakukan migrasi, ternyata penerangan yang dimiliki migran relatif lebih baik dari penduduk non migran (Tabel 5). Hal ini sejalan dengan penelitian sebelumnya yang dilakukan oleh Wodon et al. dalam penelitiannya di Meksiko mengenai migrasi dan kemiskinan. Wodon et al. (2003) menunjukkan bahwa rumah tangga migran memiliki akses terhadap listrik yang lebih baik dibandingkan dengan rumah tangga non migran.

\section{Sumber Air Minum}

Sumber air minum sangat berpengaruh terhadap kualitas air minum. Kualitas air minum sebaiknya memenuhi persyaratan minimal dari kesehatan, yaitu memenuhi persyaratan fisik, kimiawi, dan bakteriologis (Nugraheni, 2012).
Berdasarkan sumber air minum, penduduk migran yang sumber air minum utamanya adalah air kemasan dan isi ulang sebanyak 47,98 persen, jauh lebih banyak dibandingkan penduduk non migran yang hanya berjumlah 25,39 persen (Tabel 6).

Sedangkan sumber air minum sumur pompa, dan mata air, justru lebih banyak digunakan sebagai sumber air minum oleh penduduk non migran. Melihat hasil olah berdasarkan sumber air minum tersebut, dapat disimpulkan penduduk migran lebih mampu untuk mengonsumsi air minum berbayar yaitu leding, air isi ulang, dan air kemasan, dibandingkan dengan penduduk non migran yang lebih banyak mengonsumsi air minum tidak berbayar yang bersumber dari sumur pompa, mata air, air sungai, dan lainnya. 
Tabel 6.

Persentase Sumber Air Minum Berdasarkan Klasifikasi Wilayah di Indonesia Tahun 2015

\begin{tabular}{|c|c|c|}
\hline Wilayah & Migran & Non Migran \\
\hline $\begin{array}{l}\text { Air Kemasan/ } \\
\text { Isi Ulang }\end{array}$ & 47,98 & 25,39 \\
\hline Leding & 12,43 & 12,01 \\
\hline Pompa dan Sumur & 31,33 & 44,86 \\
\hline Mata Air & 5,12 & 12,84 \\
\hline Air Sungai & 0,85 & 2,10 \\
\hline Air Hujan & 2,16 & 2,63 \\
\hline Lainnya & 0,13 & 0,17 \\
\hline Jumlah & 100 & 100 \\
\hline
\end{tabular}

Sumber: Data Supas 2015 (diolah)

\section{Fasilitas BAB}

Air bersih dan fasilitas sanitasi yang layak merupakan kebutuhan dasar bagi kesehatan manusia (UN, 2010). Rumah tangga yang belum memiliki fasilitas sanitasi sendiri atau bersama dengan rumah tangga lain, dianggap belum memiliki fasilitas sanitasi yang layak. Selain itu kloset yang digunakan adalah leher angsa dan tempat pembuangan akhir berupa Instalasi Pengolahan Air Limbah (IPAL) atau tangki septik (BPS, 2018).

Tabel 7.

Persentase Jenis Lantai Rumah Migran Berdasarkan Pulau di Indonesia

Tahun 2015

\begin{tabular}{cccccc}
\hline Status & $\begin{array}{c}\text { Milik } \\
\text { Sendiri }\end{array}$ & Bersama & Umum & $\begin{array}{c}\text { Tidak } \\
\text { Memiliki }\end{array}$ & Jumlah \\
\hline Migran & 86,51 & 7,03 & 1,43 & 5,04 & 100 \\
Non Migran & 77,25 & 6,62 & 2,67 & 13,47 & 100 \\
\hline
\end{tabular}

Sumber: Data Supas 2015 (diolah)

Dari Tabel 7 juga diketahui bahwa migran lebih cenderung untuk memiliki fasilitas BAB sendiri dibandingkan non migran. Jika hubungan antara status penduduk dengan kepemilikan fasilitas BAB diuji dengan uji $P h i$, ternyata didapat nilai Phi sebesar 0,092 dan signifikansi sebesar 0,000 (Lampiran 5). Dikarenakan p-value Phi sebesar 0,000 $<0,05$, maka dapat ditarik kesimpulan bahwa terdapat hubungan yang signifikan antara status migran dan kepemilikan fasilitas BAB. 
Tabel 8.

Hasil Uji Phi antara Status Migran dan Kepemilikan Fasilitas BAB

\begin{tabular}{llrr}
\hline & & Value & Approx. Sig. \\
\hline Nominal by Nominal & Phi & .092 & .000 \\
& Cramer's V & .092 & .000 \\
N of Valid Cases & & $3 . E 8$ & \\
\hline
\end{tabular}

Sumber: Data Supas 2015 (diolah)

\section{Kepemilikan Aset}

Tingkat kesejahteraan rumah tangga dapat diukur dengan menggunakan ukuran kepemilikan barang tahan lama serta pengeluaran kebutuhan konsumsi suatu rumah tangga (Puspitawati, 2013; Smith \& Steendijk, 2015). Rumah tangga yang memiliki aset dengan harga yang tinggi dan mampu memenuhi kebutuhannya terutama kebutuhan tambahan (sekunder dan tersier), dianggap lebih sejahtera dibandingkan dengan rumah tangga yang tidak memiliki aset. Secara umum, migran memiliki aset yang lebih baik dibandingkan dengan penduduk non migran, hal ini terlihat dari hasil oleh SUPAS 2015 pada Tabel 9. Dari hasil tersebut terlihat perbedaan yang cukup besar dalam kepemilikan kendaraan seperti mobil/truk (7,8 persen) dan sepeda motor (4,64 persen). Hal ini menunjukkan bahwa migran lebih cenderung untuk memiliki aset berharga tinggi, seperti mobil/truk dan sepeda motor tersebut. Selain itu perbedaan persentase kepemilikan yang cukup besar juga terlihat pada lemari es, pendingin ruangan $(\mathrm{AC})$, mesin cuci, dan antena parabola yang masing-masing sebesar14,62 persen, 8,77, 16,72, dan 8,98 persen. Angka tersebut menunjukkan bahwa migran juga lebih cenderung untuk mampu memiliki aset sebagai pemenuhan kebutuhan tambahan, seperti barang-barang tersebut.

Di sisi lain, persentase kepemilikan sepeda dan sampan yang lebih besar berada di penduduk non migran, dengan selisih masing-masing sebesar 2,07 persen dan 0,26 persen. Hasil ini menunjukkan bahwa penduduk non migran cenderung lebih memilih sepeda dan sampan terkait kemampuan dan pemenuhan kebutuhan, di mana kebutuhan tersebut dianggap telah dipenuhi oleh penduduk migran dengan pemenuhan yang lebih baik yaitu mobil dan sepeda motor.

Tabel 9.

Persentase Kepemilikan Aset Berdasarkan Status Migran di Indonesia Tahun 2015

\begin{tabular}{lccc}
\hline $\begin{array}{l}\text { Kepemilikan } \\
\text { Aset }\end{array}$ & Migran & $\begin{array}{c}\text { Non } \\
\text { Migran }\end{array}$ & Selisih \\
\hline Mobil/truk & 17,50 & 9,70 & 7,80 \\
Sepeda Motor & 82,16 & 77,52 & 4,64 \\
Perahu Motor & 1,84 & 1,85 & $(0,01)$ \\
Sepeda & 36,34 & 38,41 & $(2,07)$ \\
Sampan & 1,63 & 1,89 & $(0,26)$ \\
Radio/DVD & 58,78 & 55,15 & 3,63 \\
Televisi & 90,36 & 88,92 & 1,44 \\
Lemari es & 62,18 & 47,56 & 14,62 \\
AC & 17,60 & 8,83 & 8,77 \\
Mesin Cuci & 39,74 & 23,02 & 16,72 \\
Parabola & 33,05 & 24,07 & 8,98 \\
\hline
\end{tabular}

Sumber: Data Supas 2015 (diolah) 


\section{SIMPULAN}

Secara umum kesejahteraan migran sudah baik, hal ini terlihat dari kualitas rumah yang ditempati. Jika dibandingkan dengan non migran, dari sisi kualitas rumah dan kepemilikan barang tahan lama, ternyata migran cenderung untuk lebih sejahtera, hal ini terlihat dari jenis penerangan, sumber air minum yang dikonsumsi, fasilitas $\mathrm{BAB}$, serta kepemilikan barang tahan lama yang dimiliki penduduk migran, secara rata-rata cenderung lebih baik pada penduduk non migran. Penelitian ini juga menunjukkan bahwa migrasi masih dapat digunakan sebagai alat untuk meningkatkan kesejahteraan. Dari hasil tersebut, pemerintah diharapkan mampu untuk mengakomodir dan mengarahkan arah migrasi penduduk agar migran lebih mampu untuk mencapai kesejahteraannya serta adanya pemerataan penyebaran penduduk di Indonesia.

\section{DAFTAR PUSTAKA}

Amalia, F. (2012). Pengaruh Pendidikan, Pengangguran dan Inflasi Terhadap Tingkat Kemiskinan di Kawasan Timur Indonesia (KTI) Periode 2001-2010. Econosains Jurnal Online Ekonomi Dan Pendidikan, 10(2), 158-169. https://doi.org/10.21009/econosains.0102.02

BPS. (2015). Penduduk Indonesia: Hasil Survei Penduduk Antar Sensus 2015. Jakarta: BPS.

BPS. (2016). Profil Penduduk Indonesia Hasil SUPAS2015. Jakarta: BPS.

BPS. (2018). Indikator Kesejahteraan Rakyat 2018: Hunian Layak Masyarakat Berpenghasilan Rendah. Jakarta: BPS.

Bukit, N. S., \& Pitoyo, A. J. (2018). Migran Risen Di Provinsi Jawa Barat Hasil Sensus Penduduk Tahun 1980-2015. Jurnal Bumi Indonesia, 7(4), 77-87.

Elgin, C., \& Oyvat, C. (2013). Lurking in The Cities: Urbanization and The Informal Economy. Structural Change and Economic Dynamics, 27, 36-47. https://doi.org/10.1016/j.strueco.2013.06.003

Irawaty, T., \& Wahyuni, E. S. (2011). Migrasi Internasional Perempuan Desa dan Pemanfaatan Remitan di Desa Pusakajaya, Kecamatan Pusakajaya, Kabupaten Subang, Provinsi Jawa Barat. Sodality, 05(03), 297-310.

Lee, E. S. (1966). A Theory of Migration. Demography, 3(1), 47-57. https://doi.org/10.1007/S13524-011-0049-9

Mabogunje, A. L. (1970). Systems Approach to A Theory of Rural-Urban Migration. In Geographical Analysis (pp. 1-18). Ohio: The Ohio State University Press.

Mahsunah, D. (2013). Analisis Pengaruh Jumlah Penduduk, Pendidikan, dan Pengangguran Terhadap Kemiskinan Di Jawa Timur. Jurnal Pendidikan Ekonomi (JUPE), 1(3), 1-17.

Nugraheni, D. (2012). Hubungan Kondisi Fasilitas Sanitasi Dasar dan Personal Hygiene dengan Kejadian Diare di Kecamatan Semarang Utara Kota Semarang. Jurnal Kesehatan Masyarakat Universitas Diponegoro, 1(2).

Nugroho, S., \& Pitoyo, A. J. (2017). Arus Migrasi Risen di Indonesia Tahun 1980-2010. Jurnal Bumi Indonesia, 6(4). 
Padmonobo, H., Setiani, O., \& Joko, T. (2012). Hubungan Faktor-Faktor Lingkungan Fisik Rumah dengan Kejadian Pneumonia pada Balita di Wilayah Kerja Puskesmas Jatibarang Kabupaten Brebes. Jurnal Kesehatan Lingkungan Indonesia, 11(2), 194198. https://doi.org/10.14710/jkli.11.2.194-198

Puspitawati, H. (2013). Ketahanan dan Kesejahteraan Keluarga. https://doi.org/10.1017/S0033583501003705

Ravenstein, E. G. (1889). The Laws of Migration. Journal of the Royal Statistical Society, 52(2), 241-305.

Rubiarko, S. I., \& Sakti, R. K. (2013). Analisis Faktor-faktor yang Mempengaruhi Disparitas Pendapatan di Provinsi Jawa Timur Tahun 2008-2011. Jurnal Ilmiah Mahasiswa FEB, 2(1).

Smith, J., \& Steendijk, R. (2015). The International Wealth Index (IWI). Social Indicators Research, 122(1), 65-85. https://doi.org/10.1007/s1 1205-014-0683-x The

Syahputra, R. (2017). Transmisi dan Distribusi Tenaga Listrik. https://doi.org/10.1016/0024-6301(95)94318-s

Tajudin, L., Rijanta, R., Yunus, H. S., \& Giyarsih, S. R. (2015). Migrasi Internasional Perilaku Pekerja Migran Di Malaysia Dan Perempuan Ditinggal Migrasi Di Lombok Timur. Jurnal Kawistara, 5(3), 221-328. https://doi.org/10.22146/kawistara.10059

Todaro, M. P. (1969). A Model of Labor Migration and Urban Unemployment in Less Developed Countries. The American Economic Review, 59(1), 138-148. https://doi.org/10.2307/1811100

Turner, J. F. C. (1968). Housing Priorities, Settlement Patterns, and Urban Development in Modernizing Countries. Journal of the American Institute of Planners, 34(6), 354363. https://doi.org/https://doi.org/10.1080/01944366808977562

United Nation. (2010). Water for sustainable urban human settlements. Briefing Note, 1-6. https://doi.org/10.1007/s11027-005-7831-1

White, K. S., Barten, N. L., Crouse, S., \& Crouse, J. (2014). Benefits of Migration in Relation to Nutritional Condition and Predation Risk in A Partially Migratory Moose Population. Ecology, 95(1), 225-237. Retrieved from https://www.jstor.org/stable/23597285

Wodon, Q., Angel-urdinola, D., Gonzalez-konig, G., Revah, D. O., \& Siaens, C. (2003). Migration and Poverty in Mexico's Southern States. MPRA Paper 10574. Retrieved from https://mpra.ub.uni-muenchen.de/id/eprint/10574 